\title{
Assessing the Links between Punitive Parenting, Peer Deviance, Social Isolation and Bullying Perpetration and Victimization in South Korean Adolescents
}

\author{
Jun Sung Hong \\ Wayne State University, School of Social Work \\ 5447 Woodward Avenue, Detroit, MI 48202 \\ Email: fl4684@wayne.edu \\ Phone: 313-577-9367 \\ Sungkyunkwan University, Dept. of Social Welfare \\ 25-2 Sungkyunkwan-ro, Jongro-gu, Seoul, South Korea \\ Email: fl4684@skku.edu \\ Phone: 82-2-760-0408

\section{Dong Ha Kim} \\ Chungwoon University, Dept. of Social Welfare \\ Daehagil-25, Hongseong, Chungnam, South Korea \\ Email: dhkim@ chungwoon.ac.kr \\ Phone: +82-41-630-3300
}

\author{
Alex R. Piquero \\ University of Texas Dallas \\ 800 W. Campbell Road, GR 31 \\ Richardson, TX 75080 \\ Email: apiquero@utdallas.edu \\ Phone: 972-883-2482
}

Graduate Programs in the School of Economic, Political, and Policy Sciences

\section{Author Note}

Jun Sung Hong, School of Social Work, Wayne State University, Detroit, MI \&

Department of Social Welfare, Sungkyunkwan University, Seoul, South Korea; Dong Ha Kim,

Department of Social Welfare, Chungwoon University, Incheon, South Korea; Alex R. Piquero,

Graduate Programs in the School of Economic, Political, and Policy Sciences, University of

Texas at Dallas, Richardson, TX.

Correspondence concerning this article should be addressed to Jun Sung Hong, School of

Social Work, Wayne State University, 5447 Woodward Avenue, Detroit, MI 48202 \& 
Department of Social Welfare, Sungkyunkwan University, 25-2 Sungkyunkwan-ro, Jongno-gu,

Seoul, South Korea.

Email: fl4684@wayne.edu \& f14684@skku.edu

Phone: $313-577-9367 \& 82-2-760-0408$

Fax: $313-577-8770$ 
Running head: PUNITIVE PARENTING, PEER DEVIANCE, SOCIAL ISOLATION

Assessing the Links between Punitive Parenting, Peer Deviance, Social Isolation and Bullying Perpetration and Victimization in South Korean Adolescents 


\begin{abstract}
Children who are abused at home are at an increased risk of bullying perpetration and bullying victimization. Within that context, the purpose of the present study was to test Agnew's general strain theory and the peer deviancy training hypothesis by utilizing structural equation modeling to empirically examine pathways linking punitive parenting to bullying perpetration and bullying victimization. This study adds to the literature in two important ways. First, potential mediating linkages between punitive parenting and bullying perpetration and bullying victimization were examined, including socially withdrawn behavior and deviant peer affiliation. Second, these relationships were considered in a longitudinal sample of South Korean adolescents, which is a novel examination given that parenting in South Korea is guided largely by Confucianism which reinforces parental control, restrictiveness, and a punitive nature. Results indicate that: (1) punitive parenting is directly related to bullying perpetration but not bullying victimization; (2) punitive parenting was found to have indirect effects only on bullying perpetration; (3) deviant peer affiliation increased the likelihood of bullying perpetration and victimization; and (4) socially withdrawn behavior only affected bullying perpetration via its effect on deviant peer affiliation.
\end{abstract}

Keywords: bullying; general strain theory; parenting; peer deviance; victimization; South Korea 
Since the publication and dissemination of Olweus' (1978) research on bullying, there has been a growing amount of research interest on the subject (Smith, Cowie, Olafsson, \& Liefooghe, 2002). Bullying has been widely defined in Western societies as a type of aggressive behavior, which is exhibited repeatedly towards a target who is unable to defend themselves (Olweus, 1999). Spreading from Western societies, research on this phenomenon has reached an international dimension (Smith et al., 1999). In South Korea, bullying is primarily conceptualized as jipdan-ttadolim (isolation by a group), jipdan-goeropim (harassed by a group), hakgyo pong'nyeok (school violence), or wang-tta (bullied individual; Lee, Smith, \& Monks, 2011). Over the years, scholars in South Korea have examined several antecedents that might increase the likelihood of some adolescents to be involved in school bullying, as either victims or perpetrators, with parenting style being one of the most frequently identified. The aim of the present study is to investigate both direct and indirect links between punitive parenting and adolescents' involvement in bullying in South Korea.

Unlike the case in most traditional Western countries, parenting styles in South Korea, as influenced by the traditional culture of Confucianism, are characterized as punitive (Park \& Ko, 2004). There is a growing consensus that children who are physically or verbally abused have a heightened risk of bullying (Dussich \& Maekoya, 2007; Holt, Kantor, \& Finkelhor, 2007; Wolfe et al., 2009). In South Korea, study findings also reveal that punitive parenting is positively related to children's aggressive behaviors and involvement in bullying victimization (Choi, 2014; Doh \& Kim, 2007; Hwang, Doh, \& Shin, 2008; Park \& Chae, 2011; Roh \& Sim, 2004).

Parenting has a profound impact on adolescent development, behavior, and socialization outside the home (Brown, Mounts, Lamborn, \& Steinberg, 1993; Engels, Dekovic, \& Meeus, 2002), and adolescents tend to observe and model the behavior and socialization of their parents 
in the home (see Bandura, 1977). Explanations of the link between punitive parenting and adolescents' peer relations have been primarily derived from social learning theory or social control theory (Hollist, Hughes, \& Schaible, 2009). Social learning theory postulates that after observing or experiencing abusive or aggressive behavior in the home or among peers, abused children may model such behavior when interacting with their peers (Bandura, 1977). Social control theory hypothesizes that adolescents' involvement in bullying may emerge when their bonds or ties to social institutions (e.g., family) are diminished (Pittaro, 2007).

More recently, scholars have also begun to explore the relevance of Agnew's $(1992,2006)$ general strain theory (GST) in understanding the link between punitive parenting and adolescents' involvement in bullying. Unlike earlier macro-based strain theories, GST is a socialpsychological theory, which explains certain behaviors as a response to negative emotions that are elicited by adverse experiences or relationships (Hollist et al., 2009). GST proposes that exposure to negative relationships or circumstances (e.g., punitive parenting, parent-adolescent conflict) has the potential to produce negative emotional reactions (e.g., depression, anger), which can increase the risk of involvement in peer conflicts. Antisocial involvement or victimization may be outcomes of pressures or strains that are reinforced by negative interpersonal relations or negative experiences (Jang, Song, \& Kim, 2014).

In addition, the peer deviance training hypothesis can shed light on the association between punitive parenting and adolescents' involvement in bullying. Deviancy training refers to social processes, which occur in peer interactions, that can influence subsequent involvement in antisocial behavior (Dishion, Spraklen, Andrews, \& Patterson, 1996). Derived from social learning research, deviancy training occurs when adolescents affiliate with deviant and antisocial peers and hold discussions that positively respond to rule breaking and delinquent behaviors (e.g., 
involvement in bullying; Levesque, 2011). Adolescents who are exposed to a negative home environment are unlikely to form secure attachment relationships with their caregivers. Consequently, they may learn to behave in ways that increase their risk of developing relationships with peers who engage in deviant activities (Cicchetti, Lynch, Shonk, \& Manly, 1992), subsequently increasing the risk of bullying involvement (Mouttapa, Valente, Gallaher,

Rohrbach, \& Unger, 2004; Poulin, Dishion, \& Burraston, 2001; Weiss et al., 2005).

Using a nationally representative sample of adolescents from South Korea, and informed by the theoretical insights of GST and the peer deviance training hypothesis, the present study uses structural equation modeling to examine some of the potential pathways linking punitive parenting to bullying perpetration and victimization. To further our understanding of the link between punitive parenting and adolescents' bullying and victimization, we examine this association through the mediating roles of socially withdrawn behavior and deviant peer affiliation, controlling for age, sex, and family socioeconomic status.

Prior Research

\section{Parenting and Its Link to Involvement in Bullying in South Korea}

A significant body of research in South Korea has examined the relevance of parenting in children and adolescents' involvement in bullying over the years. Despite rapid industrialization and globalization, parenting practices in South Korea remain guided by Confucianism, which reinforces parental control, restrictiveness, and punitiveness (Chao \& Tseng, 2002). A growing body of research in South Korea has found that the quality of parenting practices is significantly related to adolescents' risk of involvement in bullying (Doh \& Kim, 2007; Hwang et al., 2008; Park \& Chae, 2011; Roh \& Sim, 2004). For instance, Roh and Sim's (2004) study, which collected data from 514 elementary school students in grades 1-6, reported that parenting 
behaviors were significantly associated with bullying perpetration and victimization. Moreover, the study found that children identified as bully/victims reported the lowest parental warmthacceptance, and both victims and bully/victims showed the highest parental rejection-restriction. Hwang et al. (2008) examined the association between parents' marital conflict, maternal parenting behavior, and children's friendship quality in bully/victim groups. Their findings suggest that both bullies and victims perceived higher maternal rejection/maternal punishment than the non-involved groups.

\section{Other Mechanisms Linking Parenting and Involvement in Bullying}

Several mechanisms underlie the association between punitive parenting and adolescents' bullying and peer victimization. Children whose parents display punitive behaviors toward them may experience abuse across multiple developmental periods, which may impair their social functioning and they may internalize the experienced hostility in ways that might lead to socially withdrawn behavior (Alink, Cicchetti, Kim, \& Rogosch, 2012; Elliott, Cunningham, Linder, Colangelo, \& Lilly, 2006). Consequently, the child may be less likely to explore his or her environments and may be more likely to be socially isolated (Crittenden \& Ainsworth, 1989) and to experience peer victimization as a result (see Kingery, Erdley, Marshall, Whitaker, \& Reuter, 2010). These children are likely to avoid peer interactions, which can limit their opportunities to develop and display their social skills (Kingery et al., 2010). Because of poor social skills, they are likely to be rejected by their peers and be victimized as a result (Dill, Vernberg, Fonagy, Twemlow, \& Gammm, 2004). Because they are rejected or victimized by their conventional peers, they might consequently become 'loners' or join deviant and delinquent peer groups (see Fergusson \& Horwood, 1999). 
Deviant and delinquent peer groups may serve as a "surrogate family" to adolescents who are from an abusive or hostile home environment (Brunson \& Miller, 2001). Deviancy training within adolescent peer groups can increase youths' likelihood of bullying (Mouttapa et al., 2004; Poulin et al., 2001; Weiss et al., 2005). As studies have demonstrated, adolescents who engage in bullying spend time with peers with similar levels of deviant and aggressive behaviors (Espelage, Holt, \& Henkel, 2003; McPherson, Smith-Lovin, \& Cook, 2001). They model their behavior after those of their deviant peers, which are reinforced and rewarded by social acceptance into their peer group (Akers, 1998; McEvoy \& Welker, 2000). Relatively few studies have investigated whether deviant peer group affiliation can increase an adolescents' risk of bullying victimization. However, it is possible that adolescents who associate with deviant peer groups are exposed to deviant subculture in a high-risk location, which can place them at risk of being victimized by their peers (see, e.g., Whitbeck, Hoyt, Yoder, Cauce, \& Paradise, 2001). Further, deviant peer affiliation can increase an adolescent's likelihood of being victimized or alienated by their mainstream peer groups.

It is rare that adolescents who experience punitive parenting immediately engage in bullying or are victimized by their peers; rather, they follow complex pathways during adolescence, experiencing behavioral or relationship problems before being involved in bullying of some sort. These pathways can be considered through the lens of Agnew's (1992, 2006) GST, which proposes that a variety of different strains or stressors may increase the likelihood of delinquent behavior, such as involvement in bullying, sometimes directly and other times by increasing the likelihood of experiencing negative emotional reactions to the stressors. As postulated by the peer deviancy training hypothesis, adolescents whose parents are characterized as punitive are also likely to be exposed to deviant peer influence which can also increase the 
chances of bullying perpetration and victimization. Thus, the present study hypothesizes that punitive parenting would lead to an increase in bullying perpetration and victimization in South Korean adolescents as it operates through both socially withdrawn behavior and deviant peer affiliation.

Method

\section{Sample and Procedure}

Data were derived from the Korea Children and Youth Panel Study (KCYPS), a longitudinal study of a nationally representative sample of South Korean adolescents. Data were collected by the National Youth Policy Institute, which was sponsored by the South Korean government. The KCYPS is an annual longitudinal panel survey conducted since 2010 that utilizes proportional systematic stratified cluster sampling to select a representative sample of students in South Korea. The 78 middle schools selected for this study were randomly sampled by calculating the population rate in 12 national areas in a stratified multi-stage cluster sampling (NYPI, 2010). Analyses for the present study were based on three waves, which consisted of 2,219 adolescents from 2011 to 2013. KCYPS collected information on students' education and training; attitude towards vocation; part-time employment; leisure and activities; relationships with parents, teachers, and friends; self-concept; deviant behavior; and historical events. Information was also collected from parents on their educational level, employment and earnings, and housing circumstances.

Data were collected from students who responded to a self-reported questionnaire with an interviewer and parents who responded to a telephone interview annually. Interviews at the first wave were conducted in 2011 when the children were in grade 5 in elementary school, and interviews were conducted at the third wave in 2013 when the children were in the first year of 
middle school. The total sample used for the analysis included the 2,168 subjects who responded to at least two survey administrations.

\section{Measures}

Bullying perpetration was measured at wave 3 with the School Violence Perpetration Questionnaire developed by the Korean National Youth Policy Institute (NYPI, 2010). These scales have been widely used to measure bullying among South Korean children and adolescents and have demonstrated construct validity and high internal consistency with South Korean samples (Kim, Sung, \& Kim, 2015; Lee, Oh, \& Lee, 2014). The scale contained five items in which adolescents responded to the following statements, "I tease or make fun of others", "I socially exclude others from a group", "I hit my peers severely", "I threaten my peers", and "I extorted peers' money or goods". The response options for each of the items were "yes" (1) and "no" (0). A composite score was calculated, with higher scores indicating higher levels of bullying perpetration $(\alpha=.70)$.

Bullying victimization was measured at wave 3 with the School Violence Victimization Questionnaire developed by the Korean National Youth Policy Institute (NYPI, 2010). These scales have been widely used to measure bullying victimization among South Korean children and adolescents and have demonstrated construct validity and high internal consistency with South Korean samples (Kim, Sung, \& Kim, 2015; Lee, Oh, \& Lee, 2014). The scale contained six items in which adolescents responded to the following statements, "I am teased or made fun of", "I am socially excluded from a group", "I get hit severely by my peers", "I get threatened by my peers", "I experienced extortion of my goods or money from my peers", and "I have been severely sworn at from my peers". The response options for each of the items were "yes" (1) and 
"no" (0). A composite score was calculated, with higher scores indicating higher levels of bullying victimization $(\alpha=.69)$.

Punitive parenting was measured at wave 1, based on the Parenting Behavior Inventory developed by Huh (2004). The Parenting Behavior Inventory for South Korea children and adolescents demonstrated good construct validity (An, Son, \& Nam, 2014; Kwon, Lee, \& Nho, 2013; Woo, 2013). The scale contained four items in which adolescents responded to the following statements, "When I really do something wrong, my parents yell at me", "When I do something wrong, my parents (or guardians) hit me", "There have been several instances where my parents (or guardians) hit me so severely, bruises and marks were left on my body", and "My parents (or guardians) either yell at me or swear at me". Each item was rated on a four-point Likert scale (1 = "not at all true", 2 = "not too true", 3 = "somewhat true", 4 = "very true"). A composite score was calculated, with higher scores indicating higher levels of punitive parenting $(\alpha=.84)$.

Socially withdrawn behavior was measured at wave 2 with the translated and modified Korean version of the Child Behavior Checklist Youth Self-Report (Oh, Lee, Hong, \& Ha, 1998). The K-YSR's concurrent validity is well established by high correlations with the Korean Child Behavior Checklist (Ha, 2005). The scale contained five items in which adolescents responded to the following statements, "I feel really awkward when I'm in front of many people", "I feel embarrassed on many occasions", "I have difficulty expressing myself in front of others", "I feel shy", and "I don't like to assert myself in front of people". The response options for each of the items were based on a four-point Likert scale $(1=$ "not at all true", 2 = "not too true", $3=$ "somewhat true", 4 = "very true"). A composite score was calculated, with higher scores indicating higher levels of social withdrawal $(\alpha=.89)$. 
Deviant peer affiliation was measured at wave 2 by summing the number of friends categorized by ten delinquent acts: "Among your close friends, how many did the following acts during the last year? (1) smoking cigarette, (2) drinking alcohol, (3) school truancy, (4) teasing or calling names, (5) physical fighting, (6) hitting someone severely, (7) threatening someone, (8) taking away someone's money or things, (9) stealing someone's money or things, (10) engaging in online gambling with money. The response for each item was the number of friends involved with each delinquent behavior. A composite score was calculated, with higher scores indicating higher levels of deviant peer affiliation.

Covariates for the model included child's sex $(1=$ male, $0=$ female $)$, child's age, and family socioeconomic status based on the parents' self-report $(1=$ living very well, $7=$ living very poorly), all of which were measured at wave 1.

\section{Analyses}

Univariate analyses were conducted to describe the overall sample. Next, bivariate analyses were computed to examine the relationships among all study variables. Finally, structural path analyses with Mplus 7.0 (Muthén \& Muthén 2012) was used to test the hypothesized path model including mediating variables after controlling for sex, age, and family socioeconomic status (see Figure 1). For all model testing, we used full information maximum likelihood procedures (FIML) to deal with missing data. FIML has been evaluated as being the most efficient and least biased method, even when data are not missing at random or completely at random (Little \& Rubin, 2014).

The current data also contain non-normally distributed variables, such as peer victimization $($ skewness $=4.97$, kurtosis $=31.03)$, bullying victimization $($ skewness $=6.61$, kurtosis $=56.49$ ), and deviant peer affiliation $($ skewness $=6.46$, kurtosis $=57.27)$. Therefore, the 
robust maximum likelihood estimator (MLR) was used because it does not require the assumption of normality. It provides mean- and variance-adjusted chi-square test statistics and corrected standard errors (Muthén \& Muthén, 2012). Tests of indirect effects based on Mplus estimation assessed the strength of mediated relationships (Muthén \& Muthén, 2012).

Multiple indices were used to assess model fit, including chi-square tests, Root Mean Squared Error of Approximation (RMSEA), Standardized Root Square Mean Residual (SRMR), Comparative Fit Index (CFI), and Tucker-Lewis Index (TLI). Although the chi-square test has been used as one of many other indices of model fit, it is important to note that the chi-square values are highly sensitive to sample size and other biases (Bentler, 1990). Therefore, a significant chi-square is not a reason by itself to modify a model if other fit indices can provide a good fit (Kline, 1998). Thus, this study relied on a standard cutoff recommendation for RMSEA, SRMR, CFI, and TLI (see Hu \& Bentler, 1999). For RMSEA and the SRMR, values less than .05 indicated a good fit. For TLI and CFI, values greater than or equal to .90 indicated an acceptable model fit.

\section{Results}

\section{Descriptive Statistics}

Socio-demographic characteristics of the study participants are presented in Table 1. Among the 2,168 adolescents, $52.4 \%$ were male and $47.6 \%$ were female, and the mean age was almost 11 years old $(S D=.25$, range $10-11)$. The mean for the family socioeconomic status was $4.2(S D=2.19$, range $1-7)$. The mean for the punitive parenting was $7.1(S D=2.58$, range $4-16)$, for bullying perpetration it was $0.1(S D=0.43$, range $0-6)$, for bulling victimization it was 0.1 $(S D=0.49$, range $0-5)$, for socially withdrawn behavior it was $10.2(S D=3.77$, range 5-20), and for deviant peer affiliation it was $0.9(S D=3.14$, range $0-5)$. 
$<<$ Insert Table 1, about here >>

Correlation analyses among the study variables are displayed in Table 2, which indicated that most of the variables were significantly related to one another as anticipated. For example, punitive parenting at wave 1 was associated with more socially withdrawn behavior and deviant peer affiliation at wave 2 , and also with more bullying perpetration and bullying victimization at wave 3. We also calculated the tolerance and VIF for each independent variable in the model. All variables indicated a value of less than 10, implying little concern over multicollinearity.

$<<$ Insert Table 2, about here >>

\section{Path Analysis}

Structural equation modeling was estimated with bullying perpetration and victimization as the key outcome variables. In the model's initial estimation, the model did not fit the data well and modification indices indicated a possibility of an improved fit of the model to the data by adding two correlations: (1) between sex and socially withdrawn behavior, and (2) between sex and bullying victimization. Incorporation of these paths does have some support, as previous studies have demonstrated a significant association between sex and social withdrawal (Rubin \& Asenndorpf, 2014; Rubin, Coplan, \& Bowker, 2009). In addition, several previous studies have demonstrated that boys are more involved in bullying (Oh, 2014; Shin \& Kim, 2014). Thus, two correlations between sex and social withdrawal, and sex and bullying victimization were incorporated into the model and the model achieved a much more improved fit, one that also provided a good fit of the model to the data: $\chi^{2}(12)=17.207, p=.142$, CFI $=.972$, TLI $=.941$, RMSEA $=.014(90 \% \mathrm{CI}=.000$ to .029$)$, and $\mathrm{SRMR}=.013$.

Figure 1 presents the standardized path estimates for the final model. After adjusting for the covariates, punitive parenting was found to be positively related to socially withdrawn 
behavior $(\beta=.197, p<.001)$. Punitive parenting was also directly related to bullying perpetration $(\beta=.064, p<.05)$. However, the direct path from punitive parenting to bullying victimization was not significant $(\beta=.050, \mathrm{~ns})$. Higher levels of socially withdrawn behavior were positively related to higher levels of deviant peer affiliation $(\beta=.063, p<.01)$. However, socially withdrawn behavior was not directly related to either bullying victimization $(\beta=.019$, ns) or bullying perpetration $(\beta=.008, \mathrm{~ns})$. Deviant peer affiliation was positively related to both bullying victimization $(\beta=.099, p<.01)$ and bullying perpetration $(\beta=.102, p<.01)$.

The indirect paths between punitive parenting and bullying perpetration and victimization were also estimated. The results showed that only one significant indirect path between punitive parenting and bullying perpetration was indicated: punitive parenting $\rightarrow$ socially withdrawn behavior $\rightarrow$ deviant peer affiliation $\rightarrow$ bullying perpetration (indirect $\beta=.001, p<.05$ ). However, there were no significant indirect effects between punitive parenting and bullying victimization (indirect $\beta=.001, \mathrm{~ns}$ ).

\section{<<Insert Figure 1, about here〉>}

\section{Discussion}

Informed by General Strain Theory and the peer deviancy training hypothesis, the aim of the present study was to examine the relationships between punitive parenting and bullying perpetration and bullying victimization. The study also examined the extent to which either, neither, or both socially withdrawn behavior and deviant peer affiliation mediated that relationship in a longitudinal sample of South Korean adolescents. Unlike past research, which suggested that parenting was associated with both bullying perpetration and victimization (Hwang et al., 2008; Roh \& Sim, 2004), the present study findings showed that punitive parenting was positively associated with bullying perpetration only. It is conceivable that 
adolescents who are consistently exposed to punitive parenting at home may learn that acting out aggressively towards their peers is an appropriate response when they have conflicts with their peers. And with respect to indirect effects, results showed that punitive parenting was indirectly related to bullying perpetration but not bullying victimization.

Findings also indicate that deviant peer affiliation is related to both bullying perpetration and victimization, which also supports the peer deviancy training hypothesis as well as past research findings (Mouttapa et al., 2004; Poulin et al., 2001; Weiss et al., 2005; Whitbeck et al., 2001). When adolescents associate with deviant peers, they are likely exposed to delinquent behaviors, which could increase their risk of being involved in such behaviors. Also, since adolescents often find themselves in under-supervised and/or high-risk situations, they may increase their likelihood of being vulnerable to bullying victimization. Moreover, higher levels of socially withdrawn behavior were found to be positively linked to higher levels of bullying perpetration indirectly through deviant peer affiliation in the current study.

\section{Limitations}

The present study is not without any limitations. Conceptually, the items for bullying perpetration and victimization in the present study do not assess bullying in the formal sense as only one item measures physical aggression, while the remaining items assess relational and indirect aggression. The items do not assess power imbalances or repeated harassment, which are related components of bullying. Measures of bullying perpetration and victimization were derived from youth self-reports to specific behaviors, which may not sufficiently encompass all potential experiences in bullying. For example, the mean level of bullying perpetration and victimization in this study was relatively low, less than 1 in the range of 0 to 4 . Future studies might consider reports for peers and teachers, in addition to self-reports which could enhance the 
validity of the findings. Another limitation of the bullying measure is the response options for each of the items, which were dichotomized, making it difficult to determine discrete categories.

Regarding covariates, we did not control for previous bullying perpetration and victimization due to limitations in the data. Future studies might consider including previous experiences in bullying. Further, the measure of family socioeconomic status may be subject to some level of scrutiny. The measure was obtained through self-report of parents and the results might be different from what may be considered to be more typical measures of family socioeconomic status, such as parents' educational attainment and income level. Additionally, the present study did not consider other types of parenting practices, such as parental permissiveness, and how they might be associated with adolescents' bullying involvement. For instance, one study in South Korea had reported that bullying victims showed the highest paternal permissiveness and both victims and bully/victims reported the highest maternal permissiveness (Roh \& Sim, 2004). Future studies might, for example, investigate whether high levels of parental permissiveness are positively related to adolescents' bullying perpetration and victimization and the possible mediators linking this association. Finally, other potentially relevant mediators of the link between punitive parenting and bullying perpetration and victimization, such as depression, emotion dysregulation, and anger were not considered in the present study. Incorporation of these measures may better flesh out how Agnew's GST framework may be relevant for understanding bullying perpetration and victimization among South Korean youth.

\section{Implications for Practice}

Findings from the present study underscore the importance of considering the quality of parent-youth relationships and parenting behaviors and how they may influence adolescent 
behavioral outcomes in assessment and intervention programs in South Korea. Parenting is an important component for child socialization in general (Piquero et al., 2009, 2016), and in interventions designed to reduce adolescents' involvement in bullying (see Shetgiri, Lin, Avila, \& Flores, 2012; Ttofi \& Farrington, 2011). As such, it is imperative that practitioners working with adolescents thoroughly assess parenting behaviors and attend to any potential adverse experiences. In addition to parenting, practitioners in South Korea need to identify and assess adolescents' internalizing problems, and more specifically, socially withdrawn behavior, which may stem, in part, from punitive parenting in the home. For adolescents who are socially withdrawn, practitioners might consider an intervention or a treatment plan that increases their sense of connectedness and decreases their feeling of social isolation.

Furthermore, the quality of peer relationships in adolescents who are involved in bullying, as perpetrators or as victims, also needs to be seriously considered in the assessment. Because of the turbulence of adolescent years (Morris \& Steinberg, 2001), youth increasingly turn to their peers for social support. Those youth whose parents are characterized as punitive or neglectful may increasingly turn to non-conventional peers, which, in turn, can increase their risk of bullying perpetration and victimization. Peers have a profound influence during the adolescent time period, and the importance of social inclusion — and in particular exclusion - may alter the risk of an adolescent engaging in and/or being subject to bullying behavior (see Abou-ezzeddine et al., 2007). Thus, practitioners working with adolescents might consider interventions that are designed to promote positive peer relationships. And for the specific cultural context of South Korea where parenting practices remain guided by parental control, restrictiveness, and punitiveness, reduction of bullying perpetration and victimization in South Korea requires 
Bullying Perpetration and Victimization 18

additional research that can inform culturally-based prevention and intervention programs and services. 


\section{References}

Abou-ezzeddine, T., Schwartz, D., Chang, L., Lee-Shin, Y., Farver, J., \& Xu, Y. (2007). Positive peer relationships and risk of victimization in Chinese and South Korean children's peer groups. Social Development, 16, 106-127. doi: 10.1111/j.1467-9507.2007.00374.x

Agnew, R. (1992). Foundation for a general strain theory of crime and delinquency. Criminology, 30, 47-88. doi: 10.1111/j.1745-9125.1992.tb01093.x

Agnew, R. (2006). Pressured into crime: An overview of general strain theory. Los Angeles, CA: Roxbury.

Ahn, J. Lee, B. J., Kahng, S. K., Kim, H. L., Hwang, O. K., Lee, E. J., Shin, H. R., ...Yoo, J. P. (2016). Estimating the prevalence rate of child physical and psychological maltreatment in South Korea. Child Indicators Research. http://dx.doi.org/10.1007/s12187-016-9369-z

Akers, R. (1998). Social learning and social structure: A general theory of crime and deviance. Boston: Northeastern University Press.

Alink, L. R. A., Cicchetti, D., Kim, J., \& Rogosch, F. A. (2012). Longitudinal associations among child maltreatment, social functioning, and cortisol regulation. Developmental Psychology, 48, 224-236. http://dx.doi.org/10.1037/a0024892

An, J. Y., Son, Y. E., \& Nam, S. I. (2014). The effects of abuse and neglect from parents on children's school adjustment: Mediating effect of aggression. Korean Journal of Youth Studies, 21, 261-284.

Bandura, A. (1977). Social learning theory. Englewood Cliffs, NJ: Prentice-Hall.

Bentler, P. M. (1990). Comparative fit indexes in structural models. Psychological Bulletin, 107, 238. http://dx.doi.org/10.1037/0033-2909.107.2.238 
Brown, B. B., Mounts, N., Lamborn, S. D., \& Steinberg, L. (1993). Parenting practices and peer group affiliation in adolescence. Child Development, 64, 467-482. http://dx.doi.org/10.1111.j.1467-8624.1993.tb02922.x

Brunson, R. K., \& Miller, J. (2001). Girls and gangs. In C. Renzetti \& L. Goodstein (Eds.), From women, crime, and criminal justice: Original feminist readings (pp. 44-59). Los Angeles, CA: Roxbury Publishing, Co.

Chao, R., \& Tseng, V. (2002). Parenting of Asians. In M. H. Bornstein (Ed.), Handbook of parenting: Social conditions and applied parenting ( $2^{\text {nd }}$ ed., Vol. 4, pp. 59-93). Mahwah, NJ: Lawrence Erlbaum Associates.

Choi, E. O. (2015). The effects of bullying victimization on depression-anxiety, and aggression in upper grade elementary school students: The moderating effects of attachment with parents, friends, and school. (Unpublished Master's Thesis). Yongin, South Korea: Kangnam University.

Choi, I. (2014). The effects of preschool children's language ability, emotion regulation, and mothers' parenting behavior on peer competence and aggressive behavior. Journal of Korean Home Management Association, 32, 47-58.

Cicchetti, D., Lynch, M., Shonk, S., \& Manly, J. T. (1992). An organizational perspective on peer relationships in maltreated children. In R. Parke \& G. Ladd (Eds.), Family-peer relationships: Modes of linkage (pp. 345-383). Hillsdale, NJ: Erlbaum.

Crittenden, P. M., \& Ainsworth, M. D. S. (1989). Child maltreatment and attachment theory. In D. Cicchetti \& V. Carlson (Eds.), Child maltreatment: Theory and research on the causes and consequences of child abuse and neglect (pp. 432-463). New York: Cambridge University Press. 
Dill, E. J., Vernberg, E. M., Fonagy, P., Twemlow, S. W., \& Gamm, B. K. (2004). Negative affect in victimized children: The role of social withdrawal, peer rejection, and attitudes toward bullying. Journal of Abnormal Child Psychology, 32, 159-173. http://dx.doi.org/ 10.1023/B:JACP.0000019768.31348.81

Dishion, T. J., Spraklen, K. M., Andrews, D. W., \& Patterson, G. R. (1996). Deviancy training in male adolescent friendships. Behavior Therapy, 27, 373-390. https://doi.org/10.1016/S0005-7894(96)80023-2

Doh, H. S., Kim, S. M. (2007). Correlates of peer victimization in boys and girls: Maternal parenting and children's self-esteem. Journal of Korean Home Management Association, 24, 117-126.

Dussich, J. P. J., \& Maekoya, C. (2007). Physical child harm and bullying-related behaviors: A comparative study in Japan, South Africa, and the United States. International Journal of Offender Therapy and Comparative Criminology, 51, 495-509. http://dx.doi.org/ 10.1177/0306624X06298463

Elliott, G., Cunningham, S. M., Linder, M., Colangelo, M., \& Lilly, M. (2006). Child physical abuse and self-perceived social isolation among adolescents. Journal of Interpersonal Violence, 20, 1663-1684. http://dx.doi.org/10.1177/0886260505281439

Engels, R. C. M. E., Dekovic, M., \& Meeus, W. (2002). Parenting practices, social skills and peer relationships in adolescence. Social Behavior and Personality: An International Journal, 30, 3-17. https://doi.org/10.2224.sbp.2002.30.1.3

Espelage, D. L., Holt, M. K., \& Henkel, R. R. (2003). Examination of peer-group contextual effects on aggression during early adolescence. Child Development, 74, 205-220. doi: $10.1111 / 1467-8624.00531$ 
Bullying Perpetration and Victimization 22

Fergusson, D. M., \& Horwood, L. J. (1999). Prospective childhood predictors of deviant peer affiliations in adolescence. The Journal of Child Psychology and Psychiatry and Allied Disciplines, 40, 581-592.

Ha, E. H. (2005). A validation study of the Korean youth self-report (K-YSR). Journal of Child Study, 18, 83-114.

Hollist, D. R., Hughes, L. A., \& Schaible, L. M. (2009). Adolescent maltreatment, negative emotion, and delinquency: An assessment of general strain theory and family-based strain. Journal of Criminal Justice, 37, 379-387.

https://doi.org/10.1016/j.jcrimjus.2009.06.005

Holt, M. K., Kantor, G. K., \& Finkelhor, D. (2008). Parent/child concordance about bullying involvement and family characteristics related to bullying and peer victimization. Journal of School Violence, 8, 42-63. http://dx.doi.org/10.1080/15388220802067813

Hu, L., \& Bentler, P. M. (1999). Cutoff criteria for fit indexes in covariance structure analysis: Conventional criteria versus new alternatives. Structural Equation Modeling, 6, 1-55. http://dx.doi.org/10.1080/10705519909540118

Huh, M. Y. (2004). The study for the development and validation of an inventory for parenting behavior perceived by adolescents, Korean Adolescents Counselling Research, 12, 170189.

Hwang, E. Y., Sim, D. H., \& Shin, J. H. (2008). Marital conflict, maternal parenting behavior, and children's friendship quality as a function of bully/victim groups. Han'guk Gajeong Gwalli Hakhoeji, 26, 419-432.

Jang, H., Song, J., \& Kim, R. (2014). Does the offline bully-victimization influence cyberbullying behavior among youths? Application of General Strain Theory. Computers 
Bullying Perpetration and Victimization 23

in Human Behavior, 31, 85-93. https://doi.org/10.1016/j.chb.2013.10.007

Kingery, J. N., Erdley, C. A., Marshall, K. C., Whitaker, K. G., \& Reuter, T. R. (2010). Peer experiences of anxious and socially withdrawn youth: An integrative review of the developmental and clinical literature. Clinical Child and Family Psychology Review, 13, 91-128. http://dx.doi.org/10.1007/s10567-009-0063-2

Kim, J. Y., Sung, S. M., \& Kim, J. B. (2015). Bully-victims and their depression, aggression, self-control and experience of domestic violence, Journal of School Social Work, 31, 83109.

Kim, Y. S., Go, Y. J., Noh, J. S., Park, M. S., Son, S. H., Seo, D. H., Kim, S. J., Choi, N. G., \& Hong, S. E. (2001). School bullying and related psychopathology in elementary school students. Journal of the Korean Neuropsychiatric Association, 40, 876-884.

Kim, Y. S., Koh, Y. J., \& Leventhal, B. L. (2004). Prevalence of school bullying in Korean middle school students. Archives of Pediatric \& Adolescent Medicine, 158, 737-741. http://dx.doi.org/10.1001/archarsh parentingedi.158.8.737

Kline, R. B. (1998). Structural Equation Modeling. New York, NY: Guilford.

Kwon, J. E., Lee, E. J., \& Nho, C. R. (2013). Mediating effects of teacher and peer relationship on the association between child abuse and neglect and school performance. Journal of Korean Society of Child Welfare, 42, 29-54.

Kwon, S. J., Park, T. W., Park, S. H., Yang, J. C., Jeong, Y. C., \& Jeong, S. G. (2012). Prevalence of school bullying and related psychopathology in children and adolescents. Korean Academy of Child and Adolescent Psychiatry, 23, 143-153.

Lee, S., Oh, I, \& Lee J. (2014). Psychosocial characteristics of bullies, victims, bully-victims among elementary school students, Korean Youth Research, 21, 391-416. 
Lee, S., Smith, P. K., \& Monks, C. P. (2011). Perceptions of bullying-like phenomena in South Korea: A qualitative approach from a lifespan perspective. Journal of Aggression, Conflict and Peace Research, 3, 210-221. https://doi.org/10.1108/175965911111877

Levesque, R. J. R. (2011). Deviancy training. In R. J. R. Levesque (Ed.), Encyclopedia of Adolescence (pp. 690-691). New York: Springer.

Little, R. J., \& Rubin, D. B. (2014). Statistical Analysis with Missing Data. Hoboken, NJ: John Wiley \& Sons.

McEvoy, A., \& Welker, R. (2000). Antisocial behavior, academic failure, and social climate: A critical review. Journal of Emotional and Behavioral Disorder, 8, 130-140. https://doi.org/10.1177/106342660000800301

McPherson, M, Smith-Lovin, L., \& Cook, J. M. (2001). Birds of a feather: Homophily in social networks. Annual Review of Sociology, 27, 415-444. http://dx.doi.org/10.1146/annurev.soc.27.1.415

Mouttapa, M., Valente, T., Gallaher, P., Rohrbach, L. A., \& Unger, J. B. (2004). Social network predictors of bullying and victimization. Adolescence, 39, 315-335.

Muthén, L. K., \& Muthén, B. O. (2012). Mplus User's Guide 6: The Comprehensive Modeling Program for Applied Researchers. Los Angeles, CA: Muthén \& Muthén.

National Youth Policy Institute. (2010). Korean children and youth panel survey manual. Seoul, South Korea: Department of Education.

Oh, I. (2014). The relations of traditional bullying, cyberbullying and types of aggression in terms of gender. Korea Journal of Counseling, 15, 1871-1885.

Oh, K. J., Lee, H. R., Hong, K. I., \& Ha, E. H. (1998). Tests of K-CBCL reliability and validity. Seoul, South Korea: Central Adjustment Research. 
Bullying Perpetration and Victimization 25

Olweus, D. (1978). Aggression in the schools: Bullies and whipping boys. Washington, DC: Hemisphere Press.

Olweus, D. (1999). Sweden. In P. K. Smith, Y. Morita, J. Junger-Tas, D. Olweus, R. Catalano, \& P. Slee (Eds.), The Nature of School Bullying: A Cross National Perspective (pp. 309323). London: Routledge.

Park, J. Y., \& Chae, K. M. (2011). The role of parenting behaviors, child's communication and problem solving skills in bullying/being bullied. Korean Journal of Psychology: General, $30,45-67$.

Park, S. Y., \& Ko, E. J. (2004). The effect of day-care, child's characteristics and maternal behavior on child aggression. Journal of Korean Home Economic Association, 22, 23-36.

Piquero, A. R., Farrington, D. P., Welsh, B. C., Tremblay, R., \& Jennings, W. G. (2009). Effects of early family/parent training programs on antisocial behavior and delinquency. Journal of Experimental Criminology, 5, 83-120. doi: 10.1007/s11292-009-9072-x

Piquero, A. R., Jennings, W. G., Diamond, B., Farrington, D. P., Tremblay, R. E., Welsh, B. C., \& Reingle Gonzalez, J. M. (2016). A meta-analysis update on the effects of early family/parent training programs on antisocial behavior and delinquency. Journal of Experimental Criminology, 12, 229-248. doi: 10.1007/s11292-016-9256-0

Pittaro, M. L. (2007). School violence and social control theory: An evaluation of the Columbine massacre. International Journal of Criminal Justice Sciences, 2, 1-12.

Poulin, F., Dishion, T. J., \& Burraston, B. (2001). 3-year iatrogenic effects associated with aggregating high-risk adolescents in cognitive-behavioral preventive interventions. Applied Developmental Science, 5, 214-224. http://dx.doi.org/10.1207/S1532480XADS0504_03 
Roh, K. S., \& Sim, H. O. (2004). Bullying and victimization with perception of parenting behaviors among elementary school children. Korean Association of Child Studies, 25, 241-257.

Rubin, K. H., \& Asendorpf, J. B. (2014). Social withdrawal, inhibition, and shyness in childhood. New York, NY: Psychology Press.

Rubin, K. H., Coplan, R. J., \& Bowker, J. C. (2009). Social withdrawal in childhood. Annual Review of Psychology, 60, 141-171. https://doi.org/10.1146/annurev.psych.60.110707.163642

Shetgiri, R., Lin, H., Avila, R. M., \& Flores, G. (2012). Parental characteristics associated with bullying perpetration in US children aged 10 to 17 years. American Journal of Public Health, 102, 2280-2286. doi: 10.2105/AJPH.2012.300725

Shields, A., \& Cicchetti, D. (2001). Parental maltreatment and emotion dysregulation as risk factors for bullying and victimization in middle childhood. Journal of Clinical Child Psychology, 30, 349-363. http://dx.doi.org/10.1207/S15374424JCCP3003_7

Shin, H., \& Kim, S. (2014). Differences in attitudes toward bullying and moral disengagement among aggression clusters in middle school students. Korean Journal of Youth Studies, $21,307-331$.

Smith, P. K., Cowie, H., Olafsson, R. F., \& Liefooghe, A. P. D. (2002). Definition of bullying: A comparison of terms used, and age and gender differences, in a fourteen-country international comparison. Child Development, 73, 1119-1133. doi: 10.1111/14678624.00461

Smith, P. K., Morita, Y., Junger-Tas, J., Olweus, D., Catalano, R., \& Slee, P. (Eds.). (1999). The nature of school bullying: A cross-national perspective. New York: Routledge. 
Steinberg, L., \& Morris, A. S. (2001). Adolescent development. Annual Review of Psychology, 52, 83-110. doi: 10.1146/annurev.psych.52.1.83

Toth, S. L., Manly, J. T., \& Cicchetti, D. (1992). Child maltreatment and vulnerability to depression. Development and Psychopathology, 4, 97-112. https://doi.org/10.1017/S0954579400005587

Ttofi, M. M., \& Farrington, D. P. (2011). Effectiveness of school-based programs to reduce bullying: A systematic and meta-analytic review. Journal of Experimental Criminology, 7, 27-56. https://doi.org/10.1007/s11292-010-9109-1

Weiss, B., Caron, A., Ball, S., Tapp, J., Johnson, M., \& Weisz, J. R. (2005). Iatrogenic effects of group treatment for antisocial youths. Journal of Consulting and Clinical Psychology, 73, 1036-1044. http://dx.doi.org/10.1037/0022-006X73.6.1036

Whitbeck, L. B., Hoyt, D. R., Yoder, K. A., Cauce, A. M., \& Paradise, M. (2001). Deviant behavior and victimization among homeless and runaway adolescents. Journal of Interpersonal Violence, 16, 1175-1204. doi: 10.1177/088626001016011005

Wolfe, D. A., Crooks, C. C., Chiodo, D., \& Jaffe, P. (2009). Child maltreatment, bullying, gender-based harassment, and adolescent dating violence: Making the connections. Psychology of Women Quarterly, 33, 21-24. http://dx.doi.org/10.1111/j.14716402.2008.01469

Woo, S. J. (2013). The effects of parental abuse and neglect, and children's peer attachment, on mobile phone dependency. Family and Environment Research, 51, 583-590. 


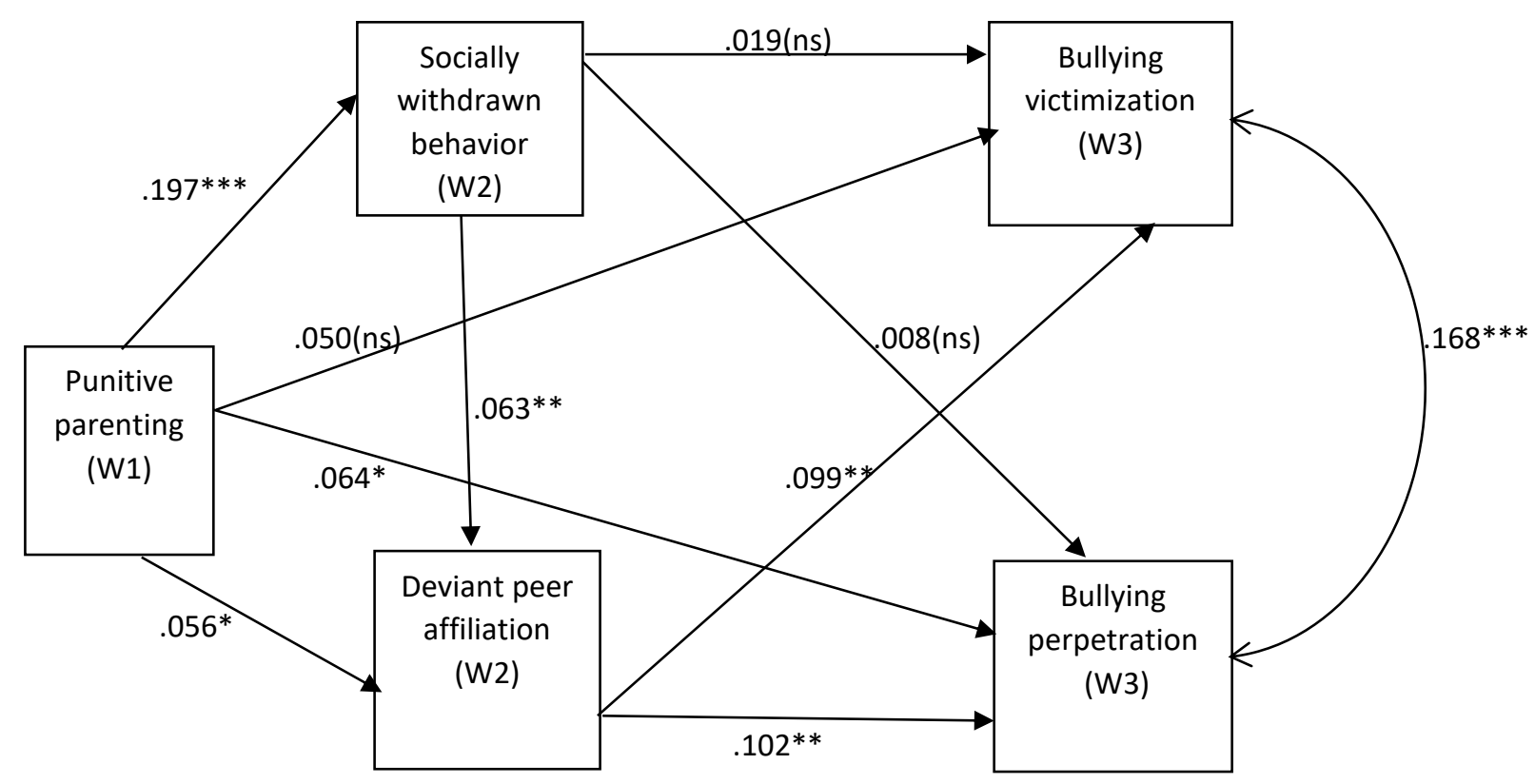

Figure 1. Standardized Path Estimates for the Final Path Model Controlling for Sex, Age, and SES

Note: Correlations between sex and socially withdrawn behavior and sex and peer victimization in this model are not shown.

$* p<.05 ; * * p<.01 ; * * * p<.001$ 
Table 1. Descriptive Statistics for the Study Variables at Baseline $(N=2,168)$

\begin{tabular}{lccc}
\hline Variables & $\begin{array}{c}\text { Wave 1 } \\
\% / \mathrm{M}(\mathrm{SD})\end{array}$ & $\begin{array}{c}\text { Wave 2 } \\
\mathrm{M}(\mathrm{SD})\end{array}$ & $\begin{array}{c}\text { Wave 3 } \\
\mathrm{M}(\mathrm{SD})\end{array}$ \\
\hline Sex & & & \\
$\quad$ Boy & $52.4 \%$ & & \\
$\quad$ Girl & $47.6 \%$ & & \\
Age (range 10-11) & $10.94(0.23)$ & & \\
Family SES (range 1-7) & $4.23(2.19)$ & & \\
Punitive parenting (range 4-16) & $7.06(2.58)$ & & $0.09(0.43)$ \\
Socially withdrawn behavior (range 5-20) & & $10.20(3.77)$ & $0.13(0.49)$ \\
Deviant peer affiliation (range 0-5) & & & \\
Bullying perpetration (range 0-6) & & & \\
Bullying victimization (range 0-5) & & & \\
\hline
\end{tabular}


Table 2. Bivariate Correlations of the Main Study Variables $(N=2,168)$

$\begin{array}{lllll}1 & 2 & 3 & 4 & 5\end{array}$

\begin{tabular}{llllllll}
\hline 1. Punitive parenting & - & & & \\
2. Bullying perpetration & $.061^{* *}$ & - & & & \\
3. Bullying victimization & $.069^{* *}$ & $.183^{* * *}$ & - & & \\
4. Socially withdrawn behavior & $.178^{* * *}$ & $.043^{*}$ & $.040^{*}$ & - & \\
5. Deviant peer affiliation & $.080^{* * *}$ & $.115^{* * *}$ & $.106^{* * *}$ & $.069 * *$ & - \\
\hline$* p<.05 ; * * p<.01 ; * * * p<.001$ & & & & & &
\end{tabular}

